\title{
Pathophysiology of Post-gastrectomy Hypoglycaemia
}

\author{
C. DEREK HOLDSWORTH,* M.D., M.R.C.P. ; D. TURNER, † M.SC. ; NEIL MCINTYRE, $\ddagger$ M.D., B.SC., M.R.C.P.
}

Summary: The blood glucose and plasma insulin response to oral glucose and slow intravenous infusion of glucose was determined in seven patients who had undergone partial gastrectomy or gastroenterostomy. Similar studies were conducted in normal subjects; in these experiments oral glucose administration was replaced by infusion of glucose direct into the jejunum in order to simulate the rapid gastric emptying which occurs after gastric surgery.

Peak insulin levels were much higher after oral or intrajejunal glucose, though peak blood glucose levels were higher after intravenous glucose. Despite the high insulin levels occurring with oral administration the late fall in blood glucose below fasting levels was not significantly greater after oral or intrajejunal glucose than after intravenous administration of the sugar. This does not support the concept that hyperinsulinaemia alone is responsible for reactive hypoglycaemia.

\section{Introduction}

Disturbing postprandial symptoms are common after the operations of partial gastrectomy and gastroenterostomy. Symptoms during or immediately after meals are usually attributed to local gastrointestinal responses and to accompanying cardiovascular changes. Some patients, however, experience sensations of faintness, weakness, and sweating which do not occur until one and a half to three hours after meals (Muir, 1949 ; Wells and Welbourne, 1951). These symptoms are usually attributed to the low blood glucose which can often be demonstrated during this period (Conn and Seltzer, 1955). After partial gastrectomy about one-third of the subjects show a "lag storage" curve; the blood glucose rises to an early high peak and then falls well below the fasting level during the later part of the test. Symptoms attributable to this "reactive" hypoglycaemia occur only in about one-half of the subjects in whom it is found (Evensen, 1942 ; Wells and Welbourn, 1951).

The usual explanation for reactive hypoglycaemia is that an excessive output of insulin results from the initial hyperglycaemia. Evidence against this explanation can be found in the studies of Barnes (1947), Hastings-James (1949), Muir (1949), De Laet and Van Den Broucke (1951), and Alpert et al. (1967). These workers studied patients who after partial gastrectomy suffered from reactive hypoglycaemia subsequent to the early hyperglycaemia induced by oral glucose. When pronounced hyperglycaemia was induced by intravenous glucose in the same subjects no reactive hypoglycaemia was found.

The insulin response to intrajejunal glucose is greater than that seen when the same amount of glucose is given intravenously (McIntyre et al., 1964, 1965). As oral glucose enters the jejunum rapidly after partial gastrectomy high insulin levels might therefore be expected in patients with this condition. Persistence of hyperinsulinaemia, after completion of glucose absorption, could be responsible for post-gastrectomy reactive \footnotetext{
* Senior Lecturer in Medicine, St. Bartholomew's Hospital, London
W.C.1.

t Research Fellow, Department of Medicine, Guy's Hospital Medical School, London S.E.1. ₹ Senior Lecturer, Department of Medicine, Royal Free Hospital, Lon-
don W.C.1.
}

hypoglycaemia ; the reported failure of intravenous glucose to produce a similar late hypoglycaemic response could be explained by the smaller increase in plasma insulin which occurs when glucose is administered parenterally. In this paper we describe the blood glucose and plasma insulin response to oral glucose in patients after gastric surgery, and compare this with the blood glucose and plasma insulin response to intravenous glucose in the same subjects. We have also carried out studies in normal subjects given an intrajejunal load of glucose in an attempt to mimic the effect of rapid gastric emptying.

\section{Subjects and Methods}

Seven patients (six male and one female) who had undergone gastric surgery for duodenal ulcer 1 to 15 years previously were studied. Gastroenterostomy had been performed in one (Case $4)$; in the others the operation was a Polya type of partial gastrectomy, with the addition of bilateral vagotomy in Case 3.

Each patient received glucose on two occasions. All subjects were given 50 or $60 \mathrm{~g}$. of glucose by mouth over three to five minutes. On a second occasion the same amount of glucose was given intravenously over 30 to 48 minutes, with the exception of one subject (Case 1), who received only $25 \mathrm{~g}$. intravenously. The duration of the intravenous infusion was selected in each patient to achieve a peak blood glucose level at about the same time as that anticipated after oral glucose.

Similar studies were conducted on four normal healthy male subjects. In order to simulate the rapid gastric emptying which occurs after gastric surgery the oral glucose was replaced by an intrajejunal infusion. A polyvinyl tube was introduced into the jejunum under radiological control and glucose was infused into the jejunum over 15 to 20 minutes as a $10 \%$ solution. All subjects were on a liberal carbohydrate diet, but had fasted overnight before the test. Informed consent was obtained for these studies in all cases.

Blood samples were obtained through an 18-gauge Riley needle placed in a brachial artery. Three fasting specimens were taken and sampling was continued at regular intervals for three hours. Blood glucose was measured by a specific glucose oxidase method (Huggett and Nixon, 1957) or by an automated modification of this method (Cramp, 1967). Plasma insulin was measured by a modification (Samols and Bilkus, 1964) of the original method of Yalow and Berson (1960). During some earlier studies trouble with refrigeration led to repeated thawing and refreezing of the aliquots of standard human insulin ; this led to a loss of potency. These standards were still adequate for the purpose of comparing the relative strengths of unknown insulin solutions and were used until new standard insulin was obtained. For this reason the plasma insulin results in the normal subjects are expressed not as absolute units but as "X mean fasting level."

\section{Results}

The blood glucose levels in the post-gastrectomy patients are shown in Table I and the plasma insulin levels in Table II. The blood glucose peak occurred at about the same time with the two methods of administration. In each patient given the full amount of intravenous glucose the peak blood glucose concentration was much higher after the intravenous load than 
after oral administration, the difference varying from 87 to $210 \mathrm{mg} . / 100 \mathrm{ml}$. In the patient (Case 1) who received a smaller amount intravenously the intravenous glucose peak was only $33 \mathrm{mg} . / 100 \mathrm{ml}$. higher than that after oral glucose. In all seven patients the blood glucose fell below the fasting level after oral glucose, by an amount varying from 8 to $34 \mathrm{mg}$./ $100 \mathrm{ml}$. The blood glucose also fell below the fasting level after intravenous glucose in five patients; in all except one of the seven patients the blood glucose was still falling when sampling
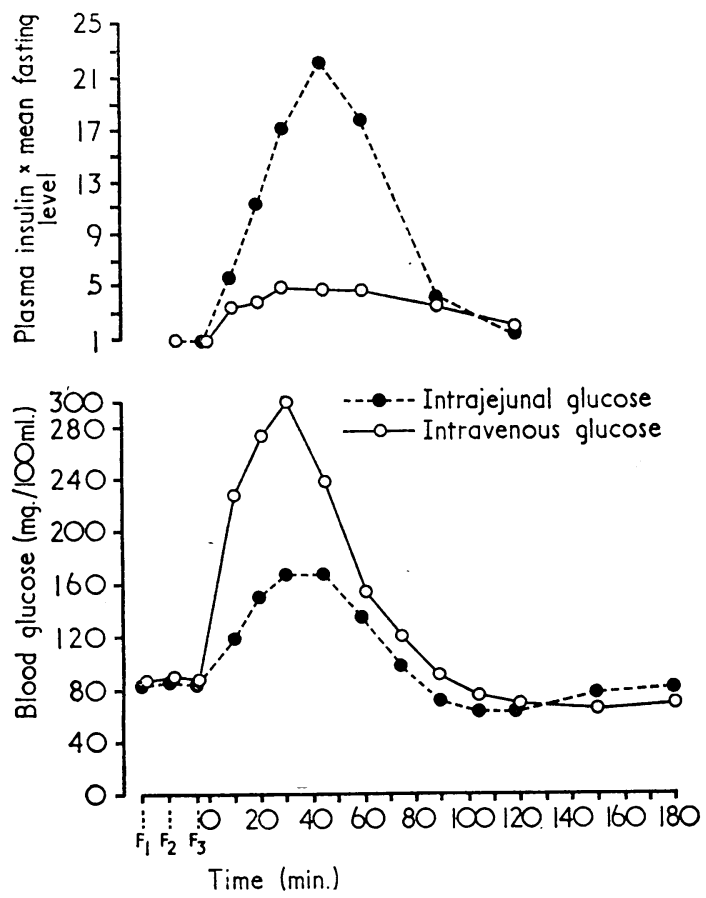

Mean blood glucose and plasma insulin response to administration of glucose in four normal subjects. On ane occasion glucose was given by intravenous infusion and on the cther occasion the same amount of the sugar was instilled direct into the jejunum. was discontinued. A fall below fasting levels could have occurred later in both cases in which it was not demonstrated.

After oral glucose the peak plasma insulin was higher than after intravenous glucose in all seven patients (Table II). There was no obvious relation between the degree of hyperglycaemia and the plasma insulin levels in individual cases. The mean peak insulin found after oral glucose occurred at 30 minutes and was $129+40 \mu \mathrm{U} . / \mathrm{ml}$. ( \pm 2 S.E.). The mean peak insulin response after intravenous glucose also occurred at 30 minutes, but was only $42 \pm 19 \mu \mathrm{U} . / \mathrm{ml}$. The fall in plasma insulin which accompanied the falling blood sugar levels after oral glucose was very rapid, so that 90 minutes after glucose administration the mean plasma insulin level $(32 \cdot 4 \pm 3 \cdot 1 \mu \mathrm{U} . / \mathrm{ml}$.) was similar to that after intravenous glucose $(33 \cdot 0 \pm 3 \cdot 1 \mu \mathrm{U} . / \mathrm{ml}$.$) .$

The mean results of the four experiments on normal subjects are shown in the Chart. The peak blood glucose levels occurred at 30 or 45 minutes in all subjects, and again were much higher after intravenous glucose administration than after delivery of a similar amount into the intestine. The rise in plasma insulin, however, was much greater after intrajejunal glucose administration. In all tests the blood sugar fell below the fasting levels 90 minutes or more after glucose administration; the fall in individual cases varied from 17 to $37 \mathrm{mg} . / 100 \mathrm{ml}$. The mean maximum fall below fasting level was $26 \mathrm{mg} . / 100 \mathrm{ml}$. after the intrajejunal load and $25 \mathrm{mg} . / 100 \mathrm{ml}$. after the intravenous dose. Hypoglycaemic symptoms were experienced by only one subject and occurred after an intrajejunal infusion.

\section{Discussion}

Roth and Meade (1965) conducted the only previous study in which plasma immunoreactive insulin has been measured in subjects after partial gastrectomy. They found that during the early part of a glucose tolerance test patients had significantly higher levels of both blood glucose and plasma insulin than normal subjects. They also gave intravenous glucose at the same time as an oral load to three normal subjects and found that the resultant pronounced hyperglycaemia was associated with much higher plasma insulin levels than those

TABLE I.-Blood Glucose Response to Oral and Intravenous Glucose in 7 Patients who had Previously had Gastric Surgery

\begin{tabular}{|c|c|c|c|c|c|c|c|c|c|c|c|c|c|c|c|c|c|c|c|c|c|}
\hline \multirow{2}{*}{$\begin{array}{l}\text { Case } \\
\text { No. }\end{array}$} & \multirow{2}{*}{$\begin{array}{c}\text { Time of } \\
\text { Infusion } \\
\text { (min.) }\end{array}$} & \multirow{2}{*}{$\begin{array}{c}\text { Route of } \\
\text { Adminis- } \\
\text { tration }\end{array}$} & \multicolumn{19}{|c|}{ Arterial Blood Glucose (mg./100 ml.) } \\
\hline & & & \multicolumn{3}{|c|}{ Fasting } & $5^{\prime}$ & $10^{\prime}$ & $15^{\prime}$ & $20^{\prime}$ & $30^{\prime}$ & $40^{\prime}$ & $50^{\prime}$ & $60^{\prime}$ & $75^{\prime}$ & $90^{\prime}$ & $105^{\prime}$ & $120^{\prime}$ & $135^{\prime}$ & $150^{\prime}$ & $165^{\prime}$ & $180^{\prime}$ \\
\hline $\begin{array}{l}6 \\
7\end{array}$ & $\begin{array}{l}40 \\
30 \\
30 \\
40 \\
48 \\
45 \\
45\end{array}$ & $\left\{\begin{array}{l}\text { Oral } \\
\text { I.V. } \\
\text { Oral } \\
\text { I.V. } \\
\text { Oral } \\
\text { I.V. } \\
\text { I.ral } \\
\text { I.V. } \\
\text { Oral } \\
\text { I.V. } \\
\text { Oral } \\
\text { I.V. } \\
\text { Oral } \\
\text { I.v. }\end{array}\right.$ & $\begin{array}{l}72 \\
67 \\
84 \\
83 \\
75 \\
60 \\
73 \\
72 \\
- \\
80 \\
80 \\
85 \\
90\end{array}$ & $\begin{array}{l}72 \\
67 \\
84 \\
82 \\
75 \\
60 \\
77 \\
74 \\
80 \\
90 \\
80 \\
80 \\
88 \\
93\end{array}$ & $\begin{array}{l}72 \\
65 \\
81 \\
83 \\
77 \\
63 \\
80 \\
72 \\
77 \\
91 \\
80 \\
78 \\
93 \\
93\end{array}$ & $\begin{array}{r}120 \\
100 \\
115 \\
87 \\
110 \\
117 \\
200 \\
125 \\
175 \\
95 \\
117 \\
126 \\
231\end{array}$ & $\begin{array}{l}143 \\
136 \\
\overline{1} \\
117 \\
140 \\
177 \\
255 \\
160 \\
198 \\
130 \\
130 \\
187 \\
231\end{array}$ & $\begin{array}{l}- \\
302 \\
273 \\
131 \\
165 \\
217 \\
325 \\
\overline{220} \\
171 \\
233 \\
236 \\
214\end{array}$ & $\begin{array}{l}207 \\
175 \\
- \\
137 \\
180 \\
237 \\
400 \\
195 \\
235 \\
195 \\
280 \\
231 \\
-\end{array}$ & $\begin{array}{l}231 \\
225 \\
287 \\
398 \\
155 \\
275 \\
277 \\
500 \\
220 \\
284 \\
225 \\
312 \\
200 \\
341\end{array}$ & $\begin{array}{l}250 \\
283 \\
223 \\
271 \\
180 \\
242 \\
290 \\
405 \\
240 \\
375 \\
\overline{235} \\
148 \\
302\end{array}$ & $\begin{array}{l}225 \\
210 \\
\overline{1} \\
157 \\
207 \\
325 \\
193 \\
370 \\
= \\
= \\
-\end{array}$ & $\begin{array}{l}185 \\
155 \\
166 \\
218 \\
125 \\
150 \\
240 \\
285 \\
178 \\
320 \\
175 \\
176 \\
319\end{array}$ & $\begin{array}{l}135 \\
127 \\
131 \\
176 \\
110 \\
132 \\
193 \\
232 \\
132 \\
275 \\
142 \\
149 \\
162 \\
231\end{array}$ & $\begin{array}{r}97 \\
155 \\
101 \\
145 \\
91 \\
109 \\
150 \\
180 \\
105 \\
240 \\
120 \\
121 \\
165 \\
181\end{array}$ & $\begin{array}{r}70 \\
85 \\
115 \\
55 \\
95 \\
124 \\
150 \\
95 \\
217 \\
110 \\
100 \\
176 \\
151\end{array}$ & $\begin{array}{r}65 \\
75 \\
70 \\
90 \\
60 \\
77 \\
100 \\
126 \\
85 \\
188 \\
85 \\
85 \\
110 \\
110\end{array}$ & $\begin{array}{r}60 \\
62 \\
63 \\
78 \\
50 \\
72 \\
87 \\
98 \\
53 \\
177 \\
70 \\
77 \\
110\end{array}$ & $\begin{array}{r}60 \\
45 \\
57 \\
61 \\
45 \\
65 \\
80 \\
85 \\
61 \\
147 \\
66 \\
71 \\
88 \\
93\end{array}$ & $\begin{array}{r}53 \\
50 \\
53 \\
55 \\
41 \\
65 \\
70 \\
72 \\
156 \\
65 \\
67 \\
88 \\
75\end{array}$ & $\begin{array}{r}50 \\
47 \\
60 \\
56 \\
47 \\
72 \\
63 \\
96 \\
128 \\
70 \\
64 \\
77 \\
79\end{array}$ \\
\hline
\end{tabular}

TABLE II.-Plasma Insulin Response to Oral and Intravenous Glucose in 7 Patients who had Previously had Gastric Surgery

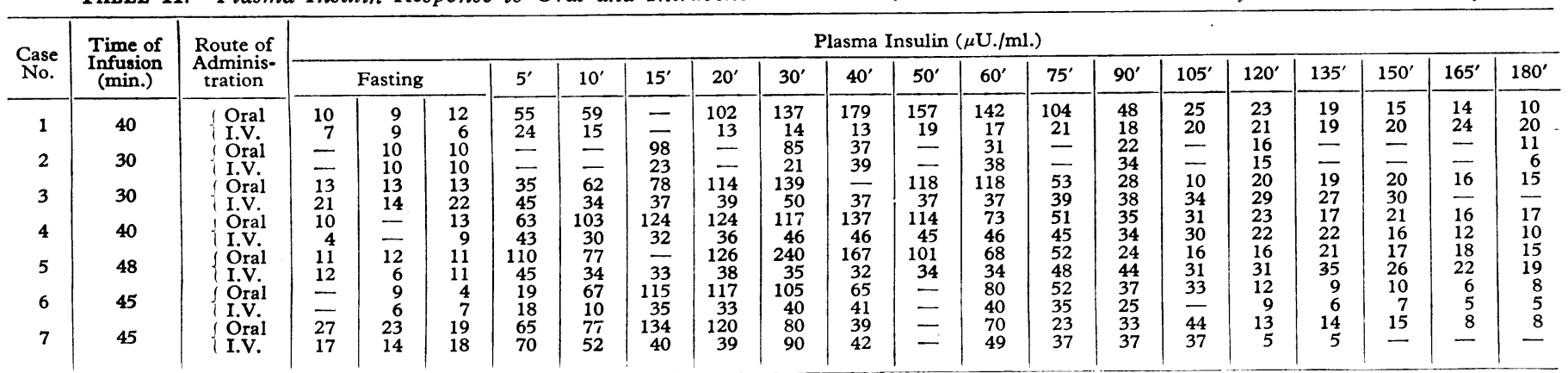


normally found after oral glucose. They concluded that the hyperglycaemia itself was an excessive stimulus to the islets of Langerhans and that the late occurrence of hypoglycaemia was explained by persistence of hyperinsulinaemia when glucose absorption was complete.

Our results preclude this simple explanation for postgastrectomy hypoglycaemia. We have confirmed that hyperglycaemia after oral glucose in gastrectomized subjects is associated with high plasma insulin levels. Nevertheless, intravenous glucose given to the same subjects, though producing a higher peak of blood glucose concentration, led to a much smaller rise in plasma insulin. Therefore hyperglycaemia per se could not account for the relatively high insulin levels which occur after oral glucose in patients with a partial gastrectomy. A similar result was found in our study of normal subjects in which rapid gastric emptying was simulated by infusion of glucose direct into the small intestine. We have suggested elsewhere that a hormonal factor is released from the jejunal wall during glucose absorption and that this stimulates the release of insulin from the pancreatic islet cells (McIntyre et al., 1965). An exaggeration of this normal response could well be responsible for the hyperinsulinaemia observed in the patients of Roth and Meade.

The fall in blood sugar below fasting levels following the initial hyperglycaemia was almost as great after intravenous glucose in our studies as with glucose given orally. The failure of some previous workers to induce hypoglycaemia with intravenous glucose may be due to their use of rapid infusion. Connard (1955) found that the rate of fall of blood glucose after a prolonged infusion was much greater than that seen after a rapid infusion and inferred from his data that insulin secretion was greater if intravenous glucose infusion was prolonged. Marks and Rose (1965) also pointed out that hypoglycaemia, after the cessation of an intravenous load, may be related to the duration of the initial hyperglycaemia rather than to its height.

In our patients the fall of arterial blood glucose below fasting values which occurred after the initial hyperglycaemia was similar whother glucose was given orally or intravenously, even though insulin levels were much higher after oral glucose. This suggests that hyperinsulinaemia per se does not adequately explain the reactive hypoglycaemia which may follow oral glucose. A similar conclusion was reached by Sussman et al. (1966), who studied 14 patients with symptomatic reactive hypoglycaemia which was not associated with gastric surgery. They found that in some patients late hypoglycaemia was associated with high initial peak insulin levels, but reactive hypoglycaemia was also found in other subjects in whom the glucose and insulin response was perfectly normal. They could find no single mechanism to explain reactive hypoglycaemia.

The fall in blood sugar below fasting levels which occurs after the initial hyperglycaemia induced by either oral or intravenous glucose may therefore be produced by some mechanism not directly related to insulin secretion. The experiments of Soskin and Allweiss (1934) support this suggestion. Blood glucose levels were maintained at a relatively constant level in pancreatectomized dogs by continuous intravenous infusion of glucose and insulin. An additional intravenous glucose load resulted in a " normal" glucose tolerance curve followed by hypoglycaemia. This response could not have been due to secretion of an extra amount of insulin. They attributed the hypoglycaemia to a persistent reduction of the supply of glucose from the liver to the blood in response to the glucose infusion.

The one factor which clearly differentiates the postgastrectomy patient from normal subjects is the pattern of gastric emptying. With an intact stomach the initial rate of emptying is rapid, but this falls exponentially (Hunt and Spurell, 1951), and under the conditions of an oral glucose tolerance test the half-time of gastric emptying is about one hour (Ḧloldsworth and Besser, 1968). It is therefore likely that glucose continues to enter the small intestine in significant amounts for two to three hours, allowing the liver sufficient time to resume its usual post-absorptive function of supplying glucose to the blood to maintain normoglycaemia. Following gastrectomy, however, regulation of gastric emptying is poor. The glucose load is delivered into the small intestine over a shorter period of time than in a normal subject and is absorbed rapidly (Holdsworth and Dawson, 1964). This will result in a relatively abrupt cessation of glucose absorption at a time when removal of glucose from the blood would be rapid under the influence of high plasma insulin levels and hepatic glucose output would be suppressed in association with rise of blood glucose and plasma insulin (Searle and Chaikoff, 1952). A delay in the resumption of appropriate glucose output by the liver might be responsible for symptomatic hypoglycaemia.

Reactive hypoglycaemia following oral glucose is common in otherwise normal individuals (Marks and Rose, 1965), and no simple explanation appears to be adequate (Sussman et al., 1966). It is possible that in such subjects abnormalities in the rate or pattern of gastric emptying may also be a factor, but such a hypothesis is speculative. Studies are now in progress, both in normal subjects and in patients before and after gastric surgery, to elucidate the relation between gastric emptying and oral glucose tolerance.

We wish to thank Professor S. Sherlock, Dr. A. M. Dawson, and Dr. Victor Wynn for kindly allowing their patients to co-operate in these studies.

This investigation was supported by grants from the Northeastern Metropolitan Regional Hospital Board and the British Insulin Manufacturers.

Requests for reprints should be sent to Dr. C. D. Holdsworth, Research Laboratories, St. Leonard's Hospital, Nuttal Street, London N.1.

\section{REFERENCES}

Alpert, S., Kerrigon, F., and Berke, R. (1967). American fournal of Gastroenterology, 47, 215 .

Barnes, C. G. (1947). Lancet, 2, 536.

Connrad, V. (1955). Acta Gastro-Enterologica Belgica, 18, 655. Conn, J. W., and Seltzer, H. S. (1955). American fournal of Medicine,

Cramp, D. G. (1967). Fournal of Clinical Pathology, 20, 910. De Lact, J. F., and Van Den Broucke, J. (1951). Acta Gastro-Entero-

Evensen, O. K. (1942). Acta Medica Scandinavica, Suppl. No. 126, p. 99.

Hastings-James, R. (1949). Lancet, 1, 814.

Holdsworth, C. D., and Dawson, A. M. (1964). Clinical Science, 27, 371.

Holdsworth, C. D., and Besser, G. M. (1968). Lancet, 2, 700.

Huggett, A. St. G., and Nixon, D. A. (1957). Lancet, 2, 368.

Hunt, J. N., and Spurell, W. R. (1951). Fournal of Physiology, 113, 157.

Marks, V., and Rose, F. C. (1965). Hypoglycaemia. Oxford, Blackwell.

McIntyre, N., Holdsworth, C. D., and Turner, D. S. (1964). Lancet, 2, 20.

McIntyre, N., Holdsworth, C. D., and Turner, D. S. (1965). Fournal of Clinical Endocrinology and Metabolism, 25, 1317.

Muir, A. (1949). British Fournal of Surgery, 37, 165.

Roth, D. A., and Meade, R. C. (1965). Diabetes, 14, 526.

Samols, E., and Bilkus, D. (1964). Proceedings of the Society of Experimental Biology and Medicine, 115, 79. Searle, G. L., and Chaikoff, I. L. (1952). American fournal of Physio-
logy, 170, 456 .

Soskin, S., and Allweiss, M. D. (1934). American fournal of Physio$\log y, 110,4$. Sussman, K. E., Stimmler, L., and Birenboim, H. (1966). Diabetes,
15, 1.

Wells, C. and Welbourn, R. (1951). British Medical fournal, 1, 546. Yalow, R. S., and Berson, S. A. (1960). Fournal of Clinical Investigation,
39, 1157 . 